\title{
Chemosphere
}

October 2018, Volume 208, Pages 764-772

http://dx.doi.org/10.1016/i.chemosphere.2018.06.039

http://archimer.ifremer.fr/doc/00443/55459/

(c) 2018 Published by Elsevier Ltd.

\section{Cellular responses of Pacific oyster (Crassostrea gigas) gametes exposed in vitro to polystyrene nanoparticles}

\author{
González-Fernández Carmen ${ }^{1,}{ }^{*}$, Tallec Kevin ${ }^{2}$, Le Goïc Nelly ${ }^{1}$, Lambert Christophe ${ }^{1}$, \\ Soudant Philippe ${ }^{1}$, Huvet Arnaud ${ }^{2}$, Suquet Marc ${ }^{2}$, Berchel Mathieu ${ }^{3}$, Paul-Pont Ika ${ }^{1}$
}

${ }^{1}$ Laboratoire des Sciences de l'Environnement Marin (LEMAR), UMR 6539 CNRS/UBO/IRD/IFREMER, Institut Universitaire Européen de la Mer (IUEM), Rue Dumont d'Urville, 29280 Plouzané, France

${ }^{2}$ Ifremer, Laboratoire des Sciences de l'Environnement Marin (LEMAR), CS 10070, 29280 Plouzané, France

${ }^{3}$ CEMCA, UMR CNRS 6521, IBSAM, UFR Sciences, Université de Bretagne Occidentale, 6 avenue Victor Le Gorgeu, 29238 Brest, France

* Corresponding author : Carmen González-Fernández, email address : carmen.gonzalezfernandez@univ-brest.fr

\begin{abstract}
:
While the detection and quantification of nano-sized plastic in the environment remains a challenge, the growing number of polymer applications mean that we can expect an increase in the release of nanoplastics into the environment by indirect outputs. Today, very little is known about the impact of nano-sized plastics on marine organisms. Thus, the objective of this study was to investigate the toxicity of polystyrene nanoplastics (NPs) on oyster (Crassostrea gigas) gametes. Spermatozoa and oocytes were exposed to four NPs concentrations ranging from 0.1 to $100 \mathrm{mg} \mathrm{L}-1$ for 1,3 and $5 \mathrm{~h}$. NPs coated with carboxylic (PS-COOH) and amine groups (PS-NH2) were used to determine how surface properties influence the effects of nanoplastics. Results demonstrated the adhesion of NPs to oyster spermatozoa and oocytes as suggested by the increase of relative cell size and complexity measured by flow-cytometry and confirmed by microscopy observations. A significant increase of ROS production was observed in sperm cells upon exposure to $100 \mathrm{mg} \mathrm{L}-1$ PS$\mathrm{COOH}$, but was not observed with PS-NH2, suggesting a differential effect according to the NP-associated functional group. Altogether, these results demonstrate that the effects of NPs occur rapidly, are complex and are possibly associated with the cellular eco-corona, which could modify NPs behaviour and toxicity.
\end{abstract}

\section{Highlights}

Nanoplastics attach to both oocytes and spermatozoa. Cellular impacts of NPs was observed on spermatozoa. PS- $\mathrm{COOH}$ exposure generated a dose-response increase in ROS production in spermatozoa. Higher impact of PS-COOH suggest an influence of particle surface properties.

Keywords : Nanoplastics, Oysters, Gametes, Cellular responses 
36 Each year, more than 320 million tons of plastic are produced in the world (Plastic

37 Europe; 2016), and a large part of this finishes as waste in the oceans: an estimated 4.8-

3812.7 million tons in 2010 (Jambeck et al., 2015). There is evidence of small particles of plastic known as microplastics (MPs, <5mm) in global waters (Barnes et al., 2009). However, because their identification is difficult, mainly due to limitations of conventional sampling methods (sampling nets have a mesh size $>300 \mu \mathrm{m}$ ) and lack of analytical techniques (Koelmans et al., 2015), little attention has been paid to smaller particles of plastic known as nanoplastics (NPs) (GESAMP, 2016). Plastic particles are considered nano in the strict sense, (i.e., defined in the same way as for non-polymer nanomaterials in the field of engineered nanoparticles) if they are $<100 \mathrm{~nm}$ in at least two of their dimensions (Klaine et al., 2012; Koelmans et al., 2015). Nevertheless, the NPs definition was enlarged to all polymeric particles $<1000 \mathrm{~nm}$ (in at least one of its dimensions) by the GESAMP (2016) because of their colloidal behaviour. Nanoplastics can be found as part of many applications such as drug delivery, cosmetics, biosensors, photonics, nanocomposites, paints, adhesives and coatings between others (Ganajan and Tijare, 2018; Guterres et al. 2007; Hernandez et al., 2017; Merinska and Dujkova, 2012; Rogach et al., 2000; Velev and Kaler, 1999). With the number of polymer applications growing each year, it is estimated that, by 2020, NPs will account for most nanomaterials on the market (Fabra et al., 2013) making the release of NPs by indirect outputs an environmental concern. Small microplastics collected at sea have recently been characterized (Ter Halle et al., 2017) and demonstrated to be increasingly

57 abundant following a power-law increase with decreasing particle size in sea surface samples (Erni-Cassola et al., 2017). 
59 Environmental effects of NPs are linked to their intrinsic features such as surface 60 charge, size, shape, functionalization and coating (Klaine et al., 2008). In addition, the interaction of NPs with biological cells will be affected by their dispersion, aggregation and agglomeration behaviour, which are dependent on the physico-chemical parameters of the surrounding media ( $\mathrm{pH}$, temperature and ionic concentration) as well as the presence/absence of natural colloids (Canesi et al., 2017). Thus, it is essential to understand how NPs behave in the marine environment and how they interact with marine organisms.

The Pacific oyster, Crassostrea gigas, has a worldwide distribution and has the highest annual production of any aquatic organisms (around 630000 tons registered worldwide in 2014), far exceeding other molluscs (mussels, clams, cockles, etc.) (FAO statistics data, 2016). During spawning, oysters release their gametes into the surrounding waters where fertilization takes place. Consequently, oocytes and spermatozoa are very vulnerable as they will be exposed to a wide range of environmental stressors present in the surrounding water, notably pollutants including micro- and nano-sized plastics, expected to be abundant in the water column (GESAMP, 2016). The effect of MPs on these organisms has recently been published. Sussarellu et al., (2016) showed a significant decrease of oocyte number and spermatozoa and oocyte quality upon polystyrene microplastic exposure of adults during gametogenesis, leading to a negative impact on D-larval yield and larval growth of experimental offspring. Working at early development stages, Cole and Galloway (2015) showed that $C$. gigas larvae can readily ingest small plastic particles $(<20 \mu \mathrm{m})$ and internalized nano-sized plastics $(<1 \mu \mathrm{m})$ without any significant reported impacts. Both studies illustrated the ingestion of small plastics by adults and early developmental stages. However, there is no information available regarding the impact of small plastics, especially nano-sized plastics, on early 
84 free living cells like oyster gametes. This is crucial information considering that the quality of spermatozoa and oocytes is essential for successful fertilisation (Boulais et al., 2015; 2017; Suquet et al., 2010). Upon spawning, fertilisation can occur within a fairly long period (a few hours) as spermatozoa movement can be maintained up to $24 \mathrm{~h}$ (Suquet et al., 2010) making this gametogenic phase very sensitive to waterborne pollutants, especially in estuarine and coastal marine habitats. In these ecosystems, environmental degradation is substantial, waters are greatly influenced by increased human expansion, and we may expect peaks of nano-sized plastics close to industrial sources, as already been observed for microplastics (Filella, 2015; Lambert and Wagner, 2016).

The objective of this study was to investigate interactions between polystyrene nanoplastics and oyster gametes. Nanoplastics exhibiting different surface functionalization with carboxylic groups $(\mathrm{COOH})$ or primary amine $\left(\mathrm{NH}_{2}\right)$, as anionic and cationic NPs, were used to assess the effects of particle surface properties, NPs behaviour in seawater and ultimate toxicity. Due to the lack of information on concentrations of nano-size particles in the environment, spermatozoa and oocytes were exposed separately to a wide range of concentrations $\left(0.1,1,10\right.$ and $100 \mathrm{mg} \mathrm{L}^{-1}$ of PS$\mathrm{NH}_{2}$ or PS-COOH) in order to identify a possible toxicity threshold. Nano-PS size, charge and aggregation state in seawater and in oocyte and spermatozoa media were monitored by Dynamic Light Scattering (DLS) during the experiment. Spermatozoa motility and cellular responses of spermatozoa and oocytes in terms of viability, cellular characteristics and Reactive Oxygen Species (ROS) production were monitored by flow cytometry at 1, 3 and $5 \mathrm{~h}$ of NPs exposure.

\section{Materials and methods}


110 Fluorescent-green $100 \mathrm{~nm}$ amino (PS-NH 2$)$ and carboxylic (PS-COOH) polystyrene

111 nanoparticles were purchased from Micromod laboratories (Germany) with an

112 Excitation/Emission: $475 \mathrm{~nm} / 510 \mathrm{~nm}$. To avoid commercial artefacts, nanobeads were 113 purchased from the same company and only differed in their functional groups. For

114 Dynamic Light Scattering analysis (DLS) the stock solutions $\left(10 \mathrm{~g} \mathrm{~L}^{-1}\right)$ were diluted in $0.2-\mu \mathrm{m}$ filtered seawater (FSW) to a concentration of $100 \mathrm{mg} \mathrm{L}^{-1}$. Size (Z-average), charge and aggregation state (polydispersity index, PDI) of nanoplastics were determined using a Zetasizer NanoZS (Malvern, United Kingdom). , in MilliQ water in triplicate, each replicate corresponding to 13 runs for the Z-average and 40 runs for Zpotential, following the protocol described in Della Torre et al. (2014). Data were analyzed using Zetasizer Nano Series software, version 6.20. The nanoplastics were also observed by transmission electronic microscopy (JeolJEM 100 CX II) to verify particle size. In brief, nanoplastics were diluted in MilliQ $\left(100 \mathrm{mg} \mathrm{L}^{-1}\right)$ and placed on a copper grid (400 nm mesh) with a carbon-coated Formvar film (Polysciences) and marked with $2 \%(\mathrm{wt} / \mathrm{vol})$ uranyl acetate to be measured.

To check the behaviour of NPs under experimental conditions, DLS measurements were also performed on particles incubated in FSW and $0.2 \mu \mathrm{m}$ filtered seminal media in the same conditions as those used during the experiment, i.e., kept in continuous movement using a Stuart rotator SB3A. Filtered seminal media were prepared by filtering spermatozoa $\left(1 \times 10^{7}\right.$ cells $\mathrm{mL}^{-1}$ in FSW) and oocyte $\left(2 \times 10^{5}\right.$ cells $\mathrm{mL}^{-1}$ in FSW) solutions on a $0.2 \mu \mathrm{m}$ filter. Nano-PS concentration was adjusted to $100 \mathrm{mg} \mathrm{L}^{-1}$ in both FSW and seminal media. Measurements were performed after 1, 3 and $5 \mathrm{~h}$ using a Zetasizer Nano as described above. 
Mature oysters from the north coast of Brittany (Aber Benoit: 48 $27^{\prime} 31^{\prime \prime} \mathrm{N}, 4^{\circ} 20^{\prime} 42^{\prime \prime}$

W) were harvested and acclimated for 1 week before gamete collection in laboratory conditions $\left[1 \mu \mathrm{m}\right.$ filtered seawater, $18^{\circ} \mathrm{C}$, continuous feeding on a mixed diet of two microalgae Chaetoceros gracilis (UTEX LB2658), T-Isochrysis (clone: T-iso; CCAP927/14)] to provide good physiological conditions prior spawning. The natural seawater used for gamete resuspension and exposure to nanoplastics was UV-treated,

140 filtered at $0.2 \mu \mathrm{m}$ and maintained at $\mathrm{T}=18^{\circ} \mathrm{C}$, salinity $38, \mathrm{pH} 8.32$ and conductivity 6 $141 \mathrm{~S} / \mathrm{m}$.

142 Spermatozoa and oocytes were collected from individual males $(n=6$; length: $110.9 \pm$ $1439.7 \mathrm{~mm})$ and individual females $(\mathrm{n}=6$; length: $129.5 \pm 8.9 \mathrm{~mm})$ by stripping according to Steele and Mulcahy (1999). Sperm motility was checked under a microscope. Final 145 concentration of $1 \times 10^{7}$ cells $\mathrm{mL}^{-1}$ and $2 \times 10^{5}$ cells $\mathrm{mL}^{-1}$ was adjusted with FSW for each individual male and female, respectively.

\subsection{Gamete exposure to nanoplastics}

Oyster' gametes from males $(n=6)$ and females $(n=6)$ were individually exposed to NPs. Four different concentrations of PS-COOH or PS- $\mathrm{NH}_{2}$ were tested separately on oocytes and spermatozoa: Control (no NPs), 0.1, 1, 10 and $100 \mathrm{mg} \mathrm{L}^{-1}$ of PS-COOH or PS-NH 2

151 which correspond to $0,1.9 \times 10^{1}, 1.9 \times 10^{2}, 1.9 \times 10^{3}$ and $1.9 \times 10^{4}$ particles spermatozoa $^{-1}$; 152 and $1.9 \times 10^{3}, 1.9 \times 10^{4}, 1.9 \times 10^{5}$ and $1.9 \times 10^{6}$ particles oocyte ${ }^{-1}$, respectively. Samples 153 were kept in continuous movement (program 3) using a Stuart rotator SB3 (Cole154 Parmer, UK) in order to prevent cell sedimentation, in a dark room at $18^{\circ} \mathrm{C}$. Sampling was performed in fresh samples after 1, 3 and $5 \mathrm{~h}$ exposure to NPs. Additionally, after 
$1563 \mathrm{~h}$ exposure, control and exposed samples of oocytes and spermatozoa were fixed in

157 formaldehyde (3\% final) for later microscopy observations.

158 2.4. Analyses

159

160

161

162

163

164

165

166

167

168

169

170

171

172

173

174

175

\subsubsection{Microscopy}

\subsubsection{Spermatozoa motility}

To measure spermatozoa motility, fresh sperm solution was mixed with FSW containing pluronic acid (PA $1 \mathrm{~g} \mathrm{~L}^{-1}$ ) (vol:vol) and transfer to a FastRead cell. The percentage of motile spermatozoa, their movement linearity and velocity (VAP: Velocity of the Average Path; $\mu \mathrm{m} \mathrm{sec}^{-1}$ ) were measured using CASA plug-in for the Image $\mathbf{J}$ software adapted for Pacific oyster spermatozoa according to Suquet et al. (2014) under a microscope (dark field, Olympus $\mathrm{B} \times 51, \times 20$ magnification), connected to a video camera (Qicam Fast, 60 frames $\mathrm{sec}^{-1}$ ).

\subsubsection{Visualization of $N P$-gamete interactions}

Once fixed in formaldehyde, both cell types emitted green fluorescence coming from the fixative (formaldehyde). In order to better localize cells and discriminate the fixative' green fluorescence from the diffuse green fluorescence of NPs, cell nucleus were labelled in blue using DAPI ((4',6-diamidino-2-phenylindole), which emits blue fluorescence upon binding to DNA. Cells were visualized using a confocal laser scanning microscope Zeiss Axio Observer Z1 coupled to a ZEISS LSM780 confocal laser module, with a Plan-Apochromat 63x/1.40 oil DIC M27 objective. Images were made using two channels: ChS1-T1 (Ex/Em: 488/599 nm) and Ch1-T2 (Ex/Em: $405 / 449 \mathrm{~nm})$. Images of spermatozoa $16.6 \times 16.6 \mu \mathrm{m}$ in size $(\mathrm{X}$-scaling $\times \mathrm{Y}$-scaling $)$ were acquired at a sampling speed of $6.7 \mu \mathrm{s} /$ pixel and a zoom of 8.1. Images of oocytes $112.4 \times 112.4 \mu \mathrm{m}$ in size $(\mathrm{X}$-scaling $\times \mathrm{Y}$-scaling) were acquired at a sampling speed of 
$1801.8 \mu \mathrm{s} /$ pixel and a zoom of 1.2. The images were obtained using ZEN 2012 SP2

181 software (Carl Zeiss Microscopy GmbH, Germany).

182 2.4.2. Flow cytometry

183 Analyses were performed using an EasyCyte Plus cytometer (Guava Technologies, 184 Millipore, Billerica, MA), equipped with a 488-nm argon laser and three fluorescence 185 detectors: green $(525 / 30 \mathrm{~nm})$, yellow $(583 / 26 \mathrm{~nm})$ and red $(680 / 30 \mathrm{~nm})$. Flow cytometry 186 analysis were performed in fresh samples with or without fluorescent probes as 187 described below. To run the different tests, cytometer' setting were established using unlabelled cell population (negative control) for which was assigned a relative (low) but non-zero fluorescence value.

\subsubsection{Cell number, relative size and complexity}

Spermatozoa and oocyte cell numbers were recorded in fresh samples without adding fluorescent probe with and without NPs, over $30 \mathrm{sec}$ at $0.12 \mu \mathrm{L} \mathrm{sec}{ }^{-1}$ flow rate for spermatozoa and at $0.59 \mu \mathrm{L} \mathrm{sec}{ }^{-1}$ for oocytes. Cells were detected and described on the flow-cytometer according to their optical characteristics obtained at small angle (Forward Scatter: FSC) and large angle (Side Scatter: SSC) giving respectively information on relative size and complexity of cells. For analysis of sperm samples, two regions were designed to discriminate single and aggregate spermatozoa.

\subsubsection{Cell mortality}

Viability was measured after 10 minutes of incubation with SYBR-14 for spermatozoa and SYBR-green for oocytes (final concentration: 1/100 commercial solution) together with propidium iodide (PI, final concentration: 10mg $\mathrm{L}^{-1}$ ) following the protocols established by Le Goïc et al. $(2013 ; 2014)$ for spermatozoa and oocytes, respectively. PI penetrates cells that have lost membrane integrity and are considered to be dead (orange/red fluorescence), whereas SYBR-green, which binds DNA, penetrates both 
205 dead and living oocytes (green fluorescence, SYBRgreen fluorescence later in the text) 206 and SYBR-14 binds DNA of live spermatozoa only. The percentage of dead oocytes

207 and spermatozoa was calculated by the ratio between the number of cells showing 208 orange/red fluorescence $(\mathrm{PI})$ and the total number of cells $\times 100$. Results were 209 expressed as percentages of dead cells.

210 A strong decrease in viability was observed in control oocytes at $5 \mathrm{~h}$ incubation, which 211 is consistent with the short life cycle of oocytes. In consequence, after $5 \mathrm{~h}$ exposure all 212 samples of oocytes were excluded from the data.

\subsubsection{Reactive Oxygen Species (ROS) production}

214 ROS production by cells was measured using 2,7-dichlorofluorescein diacetate (DCFH-

215 DA) after 50 min of incubation at $18^{\circ} \mathrm{C}$. DCFH is hydrolysed (esterase) intracellularly to 216 form DCF, which turns fluorescent green upon oxidation with ROS. The green 217 fluorescence measured is quantitatively related to the ROS production in cells and was 218 expressed in arbitrary units (A.U.).

\subsubsection{Flow cytometry data normalization}

220 After exposure to both NPs, green fluorescence level of unlabelled cells were higher in 221 the presence of nanoparticles (exposed cells) than in their absence (control cells). Thus, fluorescence values of negative controls from both, spermatozoa and oocytes, were subtracted from the labelled cells' fluorescence data obtained after addition of the different fluorescent probes: DCFH-DA (ROS production) and SYBRgreen/SYBR14 (viability). This was done to avoid any bias due to an increase in the cells' background green fluorescence observed during PS-COOH and PS- $\mathrm{NH}_{2}$ exposure. 
229 Statistical analyses were performed using STATGRAPHICS Centurion XVII and were

230 carried out separately for PS-COOH and $\mathrm{PS}-\mathrm{NH}_{2}$ conditions treatments. When the

231 requirements of normality and homogeneity of variances were met, one-way ANOVAs

232 were performed to establish significant differences between treatments at each sampling

233 time. Tukey's post-hoc test was used to test for differences among the different

234 exposure treatments with $\mathrm{P}<0.05$ as the significance level for all analyses. Arcsine or

$235 \log$ transformation was performed when necessary to meet the normality and

236 homoscedasticity criteria. Non-parametric analysis (Kruskal-Wallis test) was performed

237 when the variables did not meet the requirements of ANOVA. In addition, simple

238 regressions using the coefficient of determination $\left(\mathrm{R}^{2}\right)$ were used to investigate the

239 relationship between spermatozoa motility parameters and ROS production, with $\mathrm{P}<$

$240 \quad 0.05$ as the significance level for all analyses.

\section{Results}

243

3.1. Nanoplastic size, charge and aggregation under experimental conditions

244 DLS analysis confirmed the outlined size of NPs in MilliQ water, with a Z-average of $131.82 \pm 0.23 \mathrm{~nm}\left(\right.$ mean $\pm \mathrm{SD}$ ) and $130.83 \pm 0.32 \mathrm{~nm}$, for PS-COOH and $\mathrm{PS}-\mathrm{NH}_{2}$, respectively (Figure 1A-B). The expected size of NPs was also observed in FSW with

$247140.11 \pm 0.92 \mathrm{~nm}$ and $141.13 \pm 1.50 \mathrm{~nm}$ for PS-COOH and $\mathrm{PS}-\mathrm{NH}_{2}$, respectively. 248 Aggregation was negligible as suggested by a PdI $<0.2$ for both particle types in MilliQ and FSW conditions. Nanoparticle geometric diameter was also confirmed using transmission electron microscopy (Fig. 1C-D).

251 Results of NPs size and aggregation state monitored under constant rotation (to reproduce the incubation conditions) in FSW and in seminal media did not show any 
253 changes in size or aggregation, regardless of the particle type, media or incubation time $254 \quad(\mathrm{PdI}<0.2)$.

255 Both NPs resuspended in FSW showed a negative charge: $-2.89 \pm 7.21 \mathrm{mV}$ and $-5.69 \pm$ $2563.65 \mathrm{mV}$ for PS-COOH and PS-NH , respectively. Similar behaviour was observed in 257 oocyte and spermatozoa media, with charges of $-8.17 \pm 4.66$ and $-13.60 \pm 2.92$ for PS$258 \mathrm{COOH}$ and values of $-8.26 \pm 3.20$ and $-6.95 \pm 1.37 \mathrm{mV}$ for $\mathrm{PS}_{-} \mathrm{NH}_{2}$, respectively.

Images of spermatozoa and oocytes exposed to the highest concentration of PS-COOH are shown in Figure 2 alongside the controls. Only particles displaying significant biological effects (PS-COOH) were measured by microscopy. In order to localize cellular structures and discriminate from fixative' fluorescence (green also) and nanoplastics' fluorescence (green), cells were labelled with DAPI which allow staining nucleus DNA in blue (Fig. 2A; 2B). As a result, it was possible to localize NPs aggregates attached to the cells (Fig. 2C and 2D). In spermatozoa, aggregates of NPs were found attached mainly to the acrosome (Fig. 2C). Interaction of NPs with oocytes is shown in Fig. 2D, with oocytes covered by a semi-transparent structure formed by colloids and debris present in the medium. The aggregates of NPs appeared to be entrapped inside this structure and not directly attached to the cell.

\subsubsection{Cell number, relative size and complexity}

273 After $3 \mathrm{~h}$ and $5 \mathrm{~h}$ of exposure to $100 \mathrm{mg} \mathrm{L}^{-1} \mathrm{PS}-\mathrm{COOH}$, a significant decrease in the number of single spermatozoa was observed: $32 \%$ and $24 \%$ lower than the control (P $<0.01$ and $\mathrm{P}<0.05)$, respectively. This decrease was directly correlated with the increase 
276 in spermatozoa' aggregates for this NP condition $(\mathrm{P}<0.05$ and $\mathrm{P}<0.01$ after $3 \mathrm{~h}$ and $5 \mathrm{~h}$

277 exposure to $100 \mathrm{mg} \mathrm{L}^{-1}$ PS-COOH). No significant formation of spermatozoa'

278 aggregates was observed in treatments exposed to $\mathrm{PS}-\mathrm{NH}_{2}$, and consequently, no

279 differences in single spermatozoa number was reported. Spermatozoa exposed to the

280 highest concentration of $\mathrm{PS}-\mathrm{COOH}$ and $\mathrm{PS}-\mathrm{NH}_{2}$ showed a 4-5\% increase in relative size

281 compared with controls after 1, 3 and 5 h exposure. Spermatozoa also showed higher

282 cellular relative complexity upon exposure to 10 and $100 \mathrm{mg} \mathrm{L}^{-1}$. An increase of $24 \%$,

$28325 \%$ and $25 \%$ cellular complexity at $10 \mathrm{mg} \mathrm{L}^{-1}$ and $53 \%, 24 \%$ and $52 \%$ increase at 100

$284 \mathrm{mg} \mathrm{L}^{-1}$ was observed after 1, 3 and $5 \mathrm{~h}$ exposure to PS-COOH. Similar tendency was

285 observed upon exposure to PS- $\mathrm{NH}_{2}$ that revealed a $14 \%, 15 \%$ and $19 \%$ increase at 10

$286 \mathrm{mg} \mathrm{L}^{-1}$ whereas increased values of $59 \%, 37 \%$ and $62 \%$ were observed at $100 \mathrm{mg} \mathrm{L}^{-1}$

287 after 1, 3 and 5 h exposure, respectively. By contrast, no significant changes in oocyte

288 cell number, relative size or complexity were observed by flow cytometry in the whole

289 experiment.

290

\subsubsection{Cell mortality}

291

After exposure to the highest NP concentration $\left(100 \mathrm{mg} \mathrm{L}^{-1}\right)$, oocytes exposed to both

NPs types showed a decrease in their SYBRgreen fluorescent signal for both exposure times 1 and $3 \mathrm{~h}\left(\mathrm{P}<0.001\right.$ and $\mathrm{P}<0.01$ for $\mathrm{PS}-\mathrm{COOH}$ and $\mathrm{PS}-\mathrm{NH}_{2}$, respectively at both time points). Due to the significant decrease of SYBRgreen fluorescent observed in all females (e.g: Supplementary figure 1 for one female), fluorescent value of PI cannot be considered either. Thus, viability test for this NP condition is not conclusive and cannot be considered. For the other $3 \mathrm{NP}$ exposures $\left(0.1,1\right.$ and $\left.10 \mathrm{mg} \mathrm{L}^{-1}\right)$ where the values of SYBRgreen and PI fluorescence were validated, no significant differences in the duration. 
301 No significant differences were observed in the percentage of dead cells in spermatozoa exposed to NPs among sampling times (from 1 to $5 \mathrm{~h}$ exposure) for none of the tested

303 NPs.

\subsubsection{ROS production}

Control spermatozoa showed 17.1 $\pm 5.7(\mathrm{CV}=33.8), 24.3 \pm 8.2(\mathrm{CV}=33.7)$ and $22.4 \pm$

$9.7(\mathrm{CV}=43.55)$ A.U. of ROS production at 1,3 and $5 \mathrm{~h}$, respectively. After $1 \mathrm{~h}$ of

exposure to PS-COOH, a dose-response increase in ROS production was observed in spermatozoa exposed to 1,10 and $100 \mathrm{mg} \mathrm{L}^{-1}(\mathrm{P}<0.001)$ that was $17.4 \%, 59.4 \%$ and $121 \%$ higher respectively than in the control. After 3 and $5 \mathrm{~h}$, significant increases were only observed in spermatozoa exposed to 10 and $100 \mathrm{mg} \mathrm{L}^{-1}(\mathrm{P}<0.001$ and $\mathrm{P}<0.01$ for 3 and 5 h, respectively) with ROS values around $30 \%$ and $70 \%$ higher than in control (Figure 3). Spermatozoa exposed to PS- $\mathrm{NH}_{2}$ were not significantly affected.

ROS production in oocytes was not significantly affected by NP exposure. Levels of

314 ROS production in control oocytes ranged from 8.7 to 44.3 A.U. (24.9 \pm 11.2 A.U.; CV $315=121.5$ and $20.6 \pm 12.8$ A.U.; $C V=126.3$ after 1 and $3 \mathrm{~h}$ of incubation, respectively) showing a high inter-individual variability in stress response.

\subsubsection{Spermatozoa motility}

No significant differences were observed in the percentage of motile spermatozoa, VAP or movement linearity after exposure to NPs. Nevertheless, when spermatozoa were exposed to PS-COOH, a significantly positive correlation was found between the percentage of motile spermatozoa and spermatozoa' ROS production through the experiment $\left(R^{2}=0.12, P<0.001\right)$, particularly after 5 h exposure $\left(R^{2}=0.24, P<0.001\right)$. 


\section{Nanoplastics had similar size and charge in seawater and seminal media over time}

326

327

The most important feature of nanoplastics is their high surface area-to-volume ratio (Mattsson et al., 2015), which makes them highly reactive and prone to strongly interact with biological membranes (Rossi et al., 2014). In general, nanoplastics, as hydrophobic particles, are not thermodynamically stable and tend to aggregate very easily, forming agglomerates. However, they can become soluble if they are charged since electrostatic repulsions fight against attractive van der Waals forces as explained by the classic Derjaguin-Landau-Verwey-Overbeek (DLVO) theory (Derjaguin, 1941; Verwey et al., 1999). In the present work, oyster gametes were exposed to free single NPs of $100 \mathrm{~nm}$, as nanoplastics did not aggregate in seawater or seminal media over time. Our results are in agreement with Cai et al. (2018) which recently reported absence of aggregation in $100 \mathrm{~nm}$ polystyrene nanoplastics in $\mathrm{NaCl}$ and $\mathrm{CaCl}_{2}$ solutions charged with humic substances. This behaviour was explained by the fact that electrostatic repulsive forces increased in presence of organic matter in these solutions. Nevertheless, Cai and coauthors highlighted that aggregation behaviour of nanoplastics is influenced by complex environmental factors and further research is necessary to understand these interactions.

In the present study, a higher impact was observed with $\mathrm{PS}-\mathrm{COOH}$ than with $\mathrm{PS}-\mathrm{NH}_{2}$, contrary to previous works which revealed a higher impact of positively charged nanopolystyrene particles on different marine organisms: Crustacea (Bergami et al., 2016 ; 2017 ; Nasser and Lynch, 2016) Bivalvia (Balbi et al., 2017) Equinodea (Della Torre et al., 2014) and Chlorophyceae (Bergami et al., 2017). Positively-charged NPs have been suggested to interact more strongly with biological membranes, as demonstrated by in vitro studies with mammalian cells (Anguissola et al., 2014; Varela et al., 2012). In the 
present study, both PS-COOH and PS- $\mathrm{NH}_{2}$ showed negative charges when they were suspended in seawater. Changes on nanoplastics charge is not surprising as, once in seawater, NPs can interact rapidly with the high number of charged ions $\left(\mathrm{H}^{+}\right.$and $\left.\mathrm{OH}^{-}\right)$ present (Cole and Galloway, 2015). Additionally, in natural environments, NPs can interact with natural colloids, sediment and soils, formatting an eco-corona coating that potentially affects the fate of NPs in the water column, bioavailability, toxicity and uptake (Canesi et al., 2017; Galloway et al., 2017). Afshinnia et al. (2018) reported that natural colloids from the media (e.g., humic substances) inverted the charge in silver nanoparticles (AgNPs), suppressing the positive charge and enhancing the negative one, depending on point zero charge of the particles and the solution $\mathrm{pH}$. Nevertheless, positive charges of $50 \mathrm{~nm}$ polystyrene amino coated $\left(\mathrm{PS}-\mathrm{NH}_{2}\right)$ in seawater has been reported in other studies (Bergami et al., 2017; Della Torre et al., 2014; Manfra et al., 2017). This obliges us to ask whether the size or the commercial supplier has an impact on particles characteristics in seawater. More information about physico-chemical characteristics of nanoplastics is needed for better interpretation of NPs behave in different solutions. In addition, more powerful techniques should be used considering the limitations of DLS technique which, according to ZETASIZER manual, cannot provide accurate Z-potential between -10 to $+10 \mathrm{mV}$. Overall, in our study, NPs were from the same commercial brand and size, differing only in coated functional group and charge. As consequence, the differences in toxicity observed between PS-COOH and PS- $\mathrm{NH}_{2}$ are probably not related to the size, aggregation state or even charge of the particles, which were similar between the two particle types. Instead, the nature of the coating (carboxylic or amine) may have interacted differently with the cell membranes, medium. 
373 Nanoplastics attachment to spermatozoa and micro-scale aggregate formation

374

375

376

377

378

379 around oocytes

Spermatozoa consist of a head (between 2-3 $\mu$ m length), which contains the acrosome, an intermediate part and the flagellum $(\sim 33 \mu \mathrm{m}$ in mature spermatozoa) (DemoySchneider et al., 2013). The increase in relative size and complexity observed upon exposure to NPs is likely explained by an adhesion of NPs mostly to the spermatozoa head, as observed for PS-COOH using confocal microscopy. Similarly, an increase in relative size and relative complexity of algal cells was previously reported under exposure to metallic nanoparticles, but the localization of these particles was not confirmed by microscopy (Sendra et al., 2017).

Regarding the oocytes, NPs formed hetero-aggregates with the organic matter from seminal media that were entrapped to the cells. These aggregates were not present in all observations, which is probably due to the high variability observed in cell responses to NP exposure. Also as microscopy observations were performed on fixed samples, addition of fixative could have led to modifications regarding NPs adhesion. Nevertheless, slight modifications are expected since fixative was added after exposure of oocytes to NPs.

\section{Nanoplastics exposure affects spermatozoa more than oocytes}

Differential effects of NPs observed between spermatozoa and oocytes could be explained by differences in their membrane characteristics (Kline, 1991). In our study, we observed NPs attached to both, spermatozoa and oocytes. NPs exposure favour spermatozoa aggregation on the PS-COOH conditions. The increase of spermatozoa aggregates was concomitant to the decrease of single spermatozoa cell number observed upon exposure to PS-COOH. Conversely, no aggregation was observed in oocytes. 
397 Oocytes appeared to be covered by a transparent structure, probably from the molecules and colloids present in the medium that were absent from the spermatozoa samples. In general, the presence of proteins reduces the free energy of the NP surface, thus reducing unspecific adhesion to the membrane (Lesniak et al., 2013). Gao et al. (2017) recently reported sex-specific differences in the protein composition of the nanoparticle corona in fish and suggested that some specific proteins related to vitellogenin coated nanoparticles in developing oocytes. Such a mechanism may explain why, in our study, we observed a differential interaction of NPs between spermatozoa and oocytes. Other factors such as (i) the high inter-individual variability in oocyte quality, as previously observed for this species (Boudry et al., 2002), potentially masking the effects of NPs, (ii) the way the oocytes were collected, i.e., because the gonads were stripped, the samples would have included potentially immature oocytes (Le Goïc et al., 2014), or (iii) natural characteristics of each cell type such as the size, 40 times higher oocytes than spermatozoa and functional structures (spermatozoa with a motile flagella vs oocytes not motile and with higher lipid content) could explain the difference in NPs effects between spermatozoa and oocytes.

During the viability test in oocytes, NPs exposure $\left(100 \mathrm{mg} \mathrm{L}^{-1}\right)$ promote a significant decrease of SYBRgreen fluorescence after exposure to both PS-COOH and PS-NH This effect may be likewise caused by several factors (i) interaction of NPs with the fluorescent dye (SYBRgreen), (ii) a reduction in DNA content related to chromosome anomalies or chromosome deletions (Haberkorn et al., 2010), or even (iii) changes in the membrane permeability which may also impair the entry or retention of the SYBRgreen into the cells. Cellular membrane hyperpolarization has been demonstrated in other organisms after exposure to pollutants (Seoane et al., 2017). Unfortunately, Pacific oyster oocyte ultrastructure remains poorly described and its envelope thickness 
422 is not precisely known (Suquet, et al., 2007), which hinders a thorough understanding

423 of the biological response observed in exposed gametes in this work. Further research is

424 needed to explore the interaction between NPs and gamete membranes in greater depth,

425 which will require challenging technological developments in microscope visualization.

\section{Increase in ROS production by spermatozoa upon exposure to PS-COOH}

427 The dose-response generation of intracellular ROS observed in spermatozoa exposed to PS-COOH calls into question their subsequent ability to fertilize oocytes. Increase in ROS production and oxidative damage upon exposure to micro- and nanoplastics has been observed in other species, such as the lugworm (Arenicola marina; Browne et al., 2013), a planktonic crustacean (Daphia magna; Ma et al., 2016; Nasser and Lynch, 2016), algae (Chlorella and Scenedesmus; Bhattacharya et al., 2010), mussels (Mytilus spp.; Paul-Pont et al., 2016) and zebrafish larvae (Danio rerio; Chen et al., 2017). ROS generation and the subsequent oxidative stress have been described as the predominant mechanism leading to nano-toxicity, including DNA damage, unregulated cell signalling, changes in cell motility, cytotoxicity, apoptosis and cancer initiation and promotion (Fu et al., 2014). However, in the present study, the increase in ROS did not lead to any effects on cell motility or viability, suggesting that the oxidative stress produced was not sufficient to cause irreversible damage. From another perspective, ROS play important roles in spermatozoa physiological functions in different species including capacitation, hyperactivation and the acrosome reaction (Kothari et al., 2010; Zilli and Schiavone, 2016 in Aitken, 2017). In the present study, the positive correlation observed between the percentage of motile spermatozoa and their ROS production after being exposed to PS-COOH, particularly after $5 \mathrm{~h}$ exposure, may suggest the stimulation of spermatozoa capacitation as previously reported in mammals after an increase in intracellular ROS content (Aitken, 2017). Nevertheless, when ROS 
447 production overcomes the oxidative balance of spermatozoa, a decrease in spermatozoa

448 motility may occur as it has been reported in other studies carried out with mouse sperm 449 exposed to metallic nanoparticles (Hong et al., 2015; Kumar et al., 2001). Further 450 studies using biochemical markers of oxidative stress (MDA formation, lipid 451 peroxidation, etc.) would be useful to clarify the impacts of ROS production induced by

452 NP exposure observed here.

\section{5. Conclusion}

454 The present study evaluated the effects of nanoplastics on oyster gametes that are in 455 close contact with water-borne pollution and thus constitute very sensitive life stages. 456 Our results demonstrated adhesion of NPs to oyster spermatozoa leading to an increase 457 in relative cell size and complexity. A significant dose-response increase in ROS production by spermatozoa was demonstrated upon exposure to PS-COOH, but not with PS-NH ${ }_{2}$. Conversely, oocytes were less impacted after exposure to both NPs.

460 Differences in effects between the NPs and the two gamete cells were not related to particle size, charge or aggregation state, as tested NPs displayed similar features over time both in seawater and seminal media. Instead, results suggest that interactions with seminal biomolecules and/or cell membranes differed according to particle coating and gametes' type. It would be of further interest to investigate the nature of the eco-corona 465 formed on nanoplastics and how this modifies particle toxicity toward oyster gametes. Subsequent impacts of gamete exposure to NPs on oyster reproductive success could be assessed by studying the fertilization rate as proxy of gamete quality (Boulais et al. 2015), as well as embryo-larval development.

\section{Acknowledgements}


470 The authors thank the staff of the Ifremer facilities in Argenton. We are particularly

471 grateful to Dr. Philippe Elies from the PIMM core facilities and Olivier Lozach from the

472 COSM team at the University of Western Brittany for the microscopy observations and

473 DLS measurements. This work was supported by the NANO Project (ANR-15-CE34474 0006-02) funded by the French Agence Nationale de la Recherche (ANR). We thank 475 Helen McCombie for their help in editing the English. K. Tallec was funded by a 476 French doctoral research grant from Ifremer (50\%) and Region Bretagne (50\%).

477 References

478 Aitken, R.J., 2017. Reactive oxygen species as mediators of sperm capacitation and 479 pathological damage. Mol. Reprod. Dev. 84, 1039-1052. 480 https://doi.org/10.1002/mrd.22871

481 Anguissola, S., Garry, D., Salvati, A., O’Brien, P.J., Dawson, K.A., 2014. High content 482 analysis provides mechanistic insights on the pathways of toxicity induced by amine$\begin{array}{llll}\text { modified } & \text { polystyrene } & \text { nanoparticles. } & \text { PloS }\end{array}$ 484 https://doi.org/10.1371/journal.pone.0108025

485 Afshinnia, K., Marrone, B., Baalousha, M., 2018. Potential impact of natural organic 486 ligands on the colloidal stability of silver nanoparticles. Sci. Total Environ. 625, 1518487 1526. https://doi.org/10.1016/j.scitotenv.2017.12.299

488 Balbi, T., Camisassi, G., Montagna, M., Fabbri, R., Franzellitti, S., Carbone, C., 489 Dawson, K., Canesi, L., 2017. Impact of cationic polystyrene nanoparticles (PS-NH 2 ) 490 on early embryo development of Mytilus galloprovincialis : Effects on shell formation. 491 Chemosphere 186, 1-9. https://doi.org/10.1016/j.chemosphere.2017.07.120 
492 Barnes, D.K.a., Galgani, F., Thompson, R.C., Barlaz, M., 2009. Accumulation and

493 fragmentation of plastic debris in global environments. Philos. Trans. R. Soc. Lond. Ser.

494 B Biol. Sci. 364 (1526), 1985-1998.

495 Bhattacharya, P., Lin, S., Turner, J.P., Ke, P.C., 2010. Physical adsorption of charged 496 plastic nanoparticles affects algal photosynthesis. J. Phys. Chem. C 114, 16556-16561.

497 https://doi.org/10.1021/jp1054759

498 Bergami, E., Bocci, E., Vannuccini, M.L., Monopoli, M., Salvati, A., Dawson, K.A., 499 Corsi, I., Luisa, M., Monopoli, M., Salvati, A., Dawson, K.A., Corsi, I., 2016. Nano500 sized polystyrene affects feeding, behavior and physiology of brine shrimp Artemia 501 franciscana larvae. Ecotoxicol. Environ. Saf. 123, 18-25. 502 https://doi.org/10.1016/j.ecoenv.2015.09.021

503 Bergami, E., Pugnalini, S., Vannuccini, M.L., Manfra, L., Faleri, C., Savorelli, F., 504 Dawson, K.A., Corsi, I., 2017. Long-term toxicity of surface-charged polystyrene 505 nanoplastics to marine planktonic species Dunaliella tertiolecta and Artemia 506 franciscana. Aquat. Toxicol. 189 , 159-169.

507 https://doi.org/10.1016/j.aquatox.2017.06.008

508

509

510

511

512

513

514

515

Boudry, P., Collet, B., Cornette, F., Hervouet, V., Bonhomme, F., 2002. High variance in reproductive success of the Pacific oyster (Crassostrea gigas, Thunberg) revealed by microsatellite-based parentage analysis of multifactorial crosses. Aquaculture 204, 283296. doi:10.1016/S0044-8486(01)00841-9

Boulais, M., Corporeau, C., Huvet, A., Bernard, I., Quéré, C., Quillien, V., Fabioux, C., and Suquet, M. 2015. Assessment of oocyte and trochophore quality in Pacific oyster, Crassostrea gigas. Aquaculture 437, 201-207. https://doi.org/10.1016/j.aquaculture.2014.11.025 
516 Boulais, M., Soudant, P., Le Goïc, N., Quéré, C., Boudry, P., Suquet, M., 2017. ATP

517 content and viability of spermatozoa drive variability of fertilization success in the

518 Pacific oyster (Crassostrea gigas). Aquaculture 479, 114-119.

519 https://doi.org/10.1016/j.aquaculture.2017.05.035

520 Browne, M.A., Niven, S.J., Galloway, T.S., Rowland, S.J., Thompson, R.C., 2013.

521 Report Microplastic Moves Pollutants and Additives to Worms, Reducing Functions

522 Linked to Health and Biodiversity. CURBIO 23, 2388-2392.

523 https://doi.org/10.1016/j.cub.2013.10.012

524 Cai, L., Hu, L., Shi, H., Ye, J., Zhang, Y., Kim, H., 2018. Effects of inorganic ions and

525 natural organic matter on the aggregation of nanoplastics, Chemosphere. 197:142-151.

526 https://doi.org/10.1016/j.chemosphere.2018.01.052

527 Canesi, L., Balbi, T., Fabbri, R., Salis, A., Damonte, G., Volland, M., Blasco, J., 2017.

528 Biomolecular coronas in invertebrate species: Implications in the environmental impact

529 of nanoparticles. NanoImpact 8, 89-98. https://doi.org/10.1016/j.impact.2017.08.001

530 Chen, Q., Gundlach, M., Yang, S., Jiang, J., Velki, M., Yin, D., Hollert, H., 2017.

531 Quantitative investigation of the mechanisms of microplastics and nanoplastics toward

532 zebrafish larvae locomotor activity. Sci. Total Environ. 585, 1022-1031.

533 doi:10.1016/j.scitotenv.2017.01.156

534 Cole, M., Galloway, T.S., 2015. Ingestion of Nanoplastics and Microplastics by Pacific

535 Oyster Larvae. Environ. Sci. Technol. 49, 14625-14632.

536 https://doi.org/10.1021/acs.est.5b04099

537 Della Torre, C., Bergami, E., Salvati, A., Faleri, C., Cirino, P., Dawson, K.A., Corsi, I., 538 2014. Accumulation and Embryotoxicity of Polystyrene Nanoparticles at Early Stage of 
539 Development of Sea Urchin Embryos Paracentrotus lividus. Environ. Sci. Technol. 48,

541 Demoy-Schneider, M., Schmitt, N., Suquet, M., Labbé, C., Boulais, M., Prokopchuk,

542 G., Cosson, J., 2013. Biological characteristics of sperm in two oyster species: the

543 Pacific oyster, Crassostrea gigas, and the blacklip pearl oyster, Pinctada margaritifera.

544 In "Spermatozoa: Biology, Motility and Function and Chromosomal abnormalities",

545 Chapter 2, Nova Science Publishers Inc., Brenda T. Erickson Editor, ISBN: 978-1-63, p.

$546 \quad 15-74$

547 Derjaguin, B. V. 1941. Theory of the stability of strongly charged lyophobic sols and

548 the adhesion of strongly charged particles in solutions of electrolytes. Acta. Physiochim.

549 URS. 14, 633-662.

550 Erni-Cassola, G., Gibson, M.I., Thompson, R.C., christie-oleza, J., 2017. Lost, but

551 found with Nile red; a novel method to detect and quantify small microplastics $(20 \mu \mathrm{m}-$

$5521 \mathrm{~mm}$ ) in environmental samples. Environ. Sci. Technol., 2017, 51 (23), 13641-13648

553 FAO. 2016. The State of World Fisheries and Aquaculture 2016. Contributing to food

554 security and nutrition for all. Rome. 200 pp.

555 Fabra, M.J., Busolo, M.A., Lopez-Rubio, A., Lagaron, J.M., 2013. Nanostructured

556 bilayers in food packaging. Trends Food Sci. Technol. 31, 79-87.

557 Filella, M. 2015. Questions of size and numbers in environmental research on 558 microplastics: methodological and conceptual aspects. Environ Chem 12:527.

559 Fu, P.P., Xia, Q., Hwang, H., Ray, P.C., 2014. Mechanisms of nanotoxicity: Generation

560 of reactive oxygen species. J. Food Drug Anal. 22, 64-75.

561 https://doi.org/10.1016/j.jfda.2014.01.005 
562 Gajanan, K, Tijare, N., 2018. Nanomaterials applications. Proceedings. 5, 1093-1096.

563 Gao, J., Lin, L., Wei, A., Sepúlveda, M.S., 2017. Protein corona analysis of silver nano564 particles exposed to fish plasma. Environ. Sci. Technol. Lett. 4, 174-179.

565 Galloway, T.S., Cole, M., Lewis, C., 2017. Interactions of microplastic debris 566 throughout the marine ecosystem. Nat. Ecol. Evol. 1, 1-16. 567 https://doi.org/10.1038/s41559-017-0116

568 GESAMP. 2016. "Sources, fate and effects of microplastics in the marine environment: 569 part two of a global assessment" (Kershaw, P.J., and Rochman, C.M., eds). 570 (IMO/FAO/UNESCO-IOC/UNIDO/WMO/IAEA/UN/UNEP/UNDP Joint Group of 571 Experts on the Scientific Aspects of Marine Environmental Protection). Rep. Stud. 572 GESAMP No. 93, 220 p.

573 Guterres, S. S., Marta, P. A., \& Adriana, R. P. 2007. Polymeric nanoparticles, 574 nanospheres and nanocapsules, for cutaneous applications. Drug Target Insights, 2, $575 \quad 147-157$

576 Haberkorn, H., Lambert, C., Le Goïc, N., Moal, J., Suquet, M., Guéguen, M., Sunila, I., 577 Soudant, P., 2010. Effects of Alexandrium minutum exposure on nutrition-related 578 processes and reproductive output in oysters Crassostrea gigas. Harmful Algae 9, 427579 439. https://doi.org/10.1016/j.hal.2010.01.003

580 Hernandez, L. M., Yousefi, N., \& Tufenkji, N. 2017. Are There Nanoplastics in Your 581 Personal Care Products? Environ Sci Technol Lett. 4(7), 280-285. 582 https://doi.org/10.1021/acs.estlett.7b00187

583 Hong, F., Zhao, X., Si, W., Ze, Y., Wang, L., Zhou, Y., Hong, J., Yu, X., Sheng, L., 584 Liu, D., Xu, B., Zhang, J., 2015. Decreased spermatogenesis led to alterations of testis- 
585 specific gene expression in male mice following nano- $\mathrm{TiO}_{2}$ exposure. J. Hazard. Mater.

586

587

588

589

590

591

592

593

594

595

596

597

598

599

600

601

602

603

604

605

606

300, 718-728. https://doi.org/10.1016/j.jhazmat.2015.08.010

Jambeck, J. R., Geyer, R., Wilcox, C., Siegler, T. R., Perryman, M., Andrady, A., Narayan, R., Law, K. L. 2015. Plastic waste inputs from land into the ocean. Science, 347(6223), 768-771

Klaine, S.J., Alvarez, P.J.J., Batley, G.E., Fernandes, T.F., Handy, R.D., Lyon, D.Y., Mahendra, S., McLaughlin, M.J., Lead, J.R., 2008. Nanomaterials in the environment: behavior, fate, bioavailability, and effects. Environ. Toxicol. Chem. 27 (9), 1825-1851

Klaine, S. J., Koelmans, A. A., Horne, N., Handy, R. D., Kapustka, L., Nowack, B., \& von der Kammer, F. (2012). Paradigms to assess the environmental impact of manufactured nanomaterials. Environmental Toxicology and Chemistry, 31, 3-14.

Kline, D. 1991. Developmental Biology of membrane Transport Systems, in: Benos, D.J (Eds.), Current topics in membranes. IBSN:978-0-12-1533339-7, Vol 39, pp. 3-394.

Koelmans, A.A., Besseling, E., Shim, W.J., 2015. Nanoplastics in the aquatic environment. In: Bergmann, M., Gutow, L., Klages, M. (Eds.), Marine Anthropogenic Litter. Springer, Berlin, pp. 329-344.

Kothari, S., Thompson, A., Agarwal, A., Plessis, S.S. du, 2010. Free radicals : Their beneficial and detrimental effects on sperm function. IJEB Vol4805 May 2010.

Kumar, T., Doreswamy, K., Shrilatha, B., Muralidhara, B. 2001. Oxidative stress associated DNA damage in testis of mice: Induction of abnormal sperms and effects on fertility. Mutat. Res. Genet. Toxicol. Environ. Mutagen. 513, 103-111. https://doi.org/10.1016/S1383-5718(01)00300-X 
607 Lambert, S., Wagner, M., 2016. Characterisation of nanoplastics during the degradation

608 of $\quad$ polystyrene. $\quad$ Chemosphere 265-268.

609 https://doi.org/10.1016/j.chemosphere.2015.11.078

610 Le Goïc, N., Hégaret, H., Fabioux, C., Miner, P., Suquet, M., Lambert, C., Soudant, 611 2013. Impact of the toxic dinoflagellate Alexandrium catenella on Pacific oyster 612 reproductive output: application of flow cytometry assays on spermatozoa. Aquat. 613 Living Resour. 26, 221-228. https://doi.org/10.1051/alr/2013047

614 Le Goïc, N., Hégaret, H., Boulais, M., Béguel, J.P., Lambert, C., Fabioux, C., Soudant, 615 P., 2014. Flow cytometric assessment of morphology, viability, and production of 616 reactive oxygen species of Crassostrea gigas oocytes. Application to Toxic 617 dinoflagellate (Alexandrium minutum) exposure. Cytometry A 85, 1049-1056. doi: 618 10.1002/cyto.a.22577

619 Lesniak A., Salvati A., Santos-Martinez M. J., Radomski M. W., Dawson K. A., Åberg 620 C., 2013. Nanoparticle adhesion to the cell membrane and its effect on nanoparticle 621 uptake efficiency. J. Am. Chem. Soc. 135, 1438-1444. 10.1021/ja309812z

622 Ma, Y., Huang, A., Cao, S., Sun, F., Wang, L., Guo, H., Ji, R., 2016. Effects of 623 nanoplastics and microplastics on toxicity, bioaccumulation, and environmental fate of 624 phenanthrene in fresh water. Environ. Pollut. 219, 166-173. 625 https://doi.org/10.1016/j.envpol.2016.10.061

626 Manfra, L., Rotini, A., Bergami, E., Grassi, G., Faleri, C., Corsi, I., 2017. Comparative 627 ecotoxicity of polystyrene nanoparticles in natural seawater and reconstituted seawater 628 using the rotifer Brachionus plicatilis. Ecotoxicol. Environ. Saf. 145, 557-563. 629 https://doi.org/10.1016/j.ecoenv.2017.07.068 
630 Mattsson, K., Hansson, L.-A., Cedervall, T., 2015. Nano-plastics in the aquatic

631 environment. Environ. Sci. Process. Impacts 17, 1712-1721.

632 https://doi.org/10.1039/C5EM00227C

633 Merinska, D., Dujkova, Z., 2012. Polystyrene (nano)composites with possible anti634 bacterial effect. Mathematical Methods and Techniques in Engineering and 635 Environmental Science (ISBN: 978-1-61804-046-6)

636 Nasser, F., Lynch, I., 2016. Secreted protein eco-corona mediates uptake and impacts of 637 polystyrene nanoparticles on Daphnia magna. J. Proteomics 137, 45-51. 638 https://doi.org/10.1016/j.jprot.2015.09.005

639 Plastics Europe 2016. An analysis of European plastics production, demand and waste 640 data.Technical Report.

641 Paul-Pont, I., Lacroix, C., González Fernández, C., Hégaret, H., Lambert, C., Le Goïc, 642 N., Frère, L., Cassone, A.L., Sussarellu, R., Fabioux, C., Guyomarch, J., Albentosa, M., 643 Huvet, A., Soudant, P., 2016. Exposure of marine mussels Mytilus spp. to polystyrene 644 microplastics: Toxicity and influence on fluoranthene bioaccumulation. Environ. Pollut. 645 216, 724-737. https://doi.org/10.1016/j.envpol.2016.06.039

646 Plastics Europe 2016. An analysis of European plastics production, demand and waste 647 data.Technical Report.

648 Rogach, A., Susha, A., Caruso, F., Sukhorukov, G., Kornowski, A., Kershaw, S., 649 Möhwald, H., Eychmüller, A., Weller, H., 2000. Nano- and microengineering: 3-D 650 colloidal photonic crystals prepared from sub- $\mu \mathrm{m}$-sized polystyrene latex spheres pre651 coated with luminescent polyelectrolyte/nanocrystal shells. Adv. Mater. 12, 333-337 
652 Rossi, G., Barnoud, J., Monticelli, L., 2014. Polystyrene nanoparticles perturb lipid

653 membranes. J. Phys. Chem. Lett. 5, 241-246. https://doi.org/10.1021/jz402234c

654 Sendra, M., Yeste, P.M., Moreno-Garrido, I., Gatica, J.M., Blasco, J., 2017. CeO 2 NPs, 655 toxic or protective to phytoplankton? Charge of nanoparticles and cell wall as factors 656 which cause changes in cell complexity. Sci. Total Environ. 590-591, 304-315. 657 https://doi.org/10.1016/j.scitotenv.2017.03.007

658 Seoane, M., Esperanza, M., Cid, Á., 2017. Cytotoxic effects of the proton pump 659 inhibitor omeprazole on the non-target marine microalga Tetraselmis suecica. Aquat. 660 Toxicol. 191, 62-72. https://doi.org/10.1016/j.aquatox.2017.08.001

661 Steele, S., Mulcahy, M.F., 1999. Gametogenesis of the oyster Crassostrea gigas in 662 Southern Ireland. J. Mar. Biol. Assoc. U. K. 79, 673-686.

663 M. Suquet, M., Amourda, C., Mingant, C., Quéau, I., Lebrun, I., Brizard, R., 2007. 664 Setting of a procedure for experimental incubation of Pacific oyster (Crassostrea gigas) 665 embryos. Aquaculture. 273, 503-508.

666 Suquet, M., Labbe, C., Brizard, R., Donval, A., Le Coz, J.R., Quéré, C., Haffray, P., 667 2010. Changes in motility, ATP content, morphology and fertilisation capacity during 668 the movement phase of tetraploid Pacific oyster (Crassostrea gigas) sperm. 669 Theriogenology 74, 111-117. https://doi.org/10.1016/j.theriogenology.2010.01.021

670 Suquet M, Labbé C, Puyo S. Haffray, P., 2014. Survival, growth and reproduction of 671 cryopreserved larvae from a marine invertebrate, the Pacific oyster (Crassostrea gigas). 672 PLoS One 9:e93486, 1-6.

673 Sussarellu, R., Suquet, M., Thomas, Y., Lambert, C., Fabioux, C., Pernet, M.E.J., Le 674 Goïc, N., Quillien, V., Mingant, C., Epelboin, Y., Corporeau, C., Guyomarch, J., 
675 Robbens, J., Paul-Pont, I., Soudant, P., Huvet, A., 2016. Oyster reproduction is affected

676 by exposure to polystyrene microplastics. Proc. Natl. Acad. Sci. 113, 2430-2435.

677 https://doi.org/10.1073/pnas.1519019113

678 Ter Halle, A., Jeanneau, L., Martignac, M., Jardé, E., Pedrono, B., Brach, L., Gigault, J., 679 2017. Nanoplastic in the North Atlantic Subtropical Gyre. Environ. Sci. Technol.

680 acs.est.7b03667. https://doi.org/10.1021/acs.est.7b03667

681 Varela, J.A., Bexiga, M.G., Åberg, C., Simpson, J.C., Dawson, K.A., 2012. Quantifying 682 size-dependent interactions between fluorescently labeled polystyrene nanoparticles and 683 mammalian cells. J. Nanobiotechnology 10, 39. https://doi.org/10.1186/1477-3155-10$684 \quad \underline{39}$

685 Velev, O.D., Kaler, E.W., 1999. In situ assembly of colloidal particles into miniaturized 686 biosensors. Langmuir 15, 3693-3698. http://dx.doi.org/10.1021/la981729c.

687 Verwey, E. J. W., Overbeek, J. T. G., and Overbeek, J. T. G. 1999. Theory of the 688 stability of lyophobic colloids. Courier Corporation

689 Zilli Loredana; Schiavone, R.V.S., 2016. Role of protein 690 phosphorylation/dephosphorylation in fish sperm motility activation: State of the art and 691 perspectives. $\quad$ Aquaculture $\quad 472,80$. 692 https://doi.org/10.1016/j.aquaculture.2016.03.043 
Figure 1. Nanoplastics characterization using Dynamic Light Scattering (A, B) and Transmission Electronic Microscopy (TEM) imaging (C, D). Size distribution of $100 \mathrm{~nm}$ PS$\mathrm{COOH}(\mathrm{A})$ and $100 \mathrm{~nm}$ PS- $\mathrm{NH}_{2}$ (B) measured in triplicates (each replicate is marked in blue, red and green) using a Zetasizer Nano Series software 6.2. TEM observations of $100 \mathrm{~nm}$ PS$\mathrm{COOH}(\mathrm{C})$ and $100 \mathrm{~nm}$ PS-NH2 (D) are also presented. Scale bar: $50 \mathrm{~nm}$.

Figure 2. Confocal fluorescence microscopy carried out in fixed samples of control spermatozoa and oocytes (A, B) and spermatozoa/ oocytes exposed to $100 \mathrm{mg} \mathrm{L}^{-1} \mathrm{PS}-\mathrm{COOH}$ for $3 \mathrm{~h}$ exposure $(\mathrm{C}, \mathrm{D})$, stained with DAPI. Control cells $(\mathrm{A}, \mathrm{B})$ showed blue fluorescence coming from the DAPI dye and they has lifelike fixative' green fluorescence due to the fixation with formaldehyde. Exposed spermatozoa (C) evidenced high green fluorescence in the acrosome and in some points along the tale, coming from the aggregates of nanoplastics attached to the cell. Exposed oocytes (D) head fluorescence green coming from nanoplastics aggregates wrapped into the organic debris.

Figure 3. Intracellular reactive oxygen production (ROS) of individual' ( $n=6)$ spermatozoa after $1 \mathrm{~h}, 3 \mathrm{~h}$ and $5 \mathrm{~h}$ exposure to 4 different concentrations of PS-COOH. Significant differences between treatments are marked with lowercase letters.

\section{SUPPLEMENTARY MATERIAL}

Supplementary Figure 1 Histograms for SYBRgreen staining analysis of one female exposed to PS-COOH (1A) and PS- $\mathrm{NH}_{2}$ (1B) for $1 \mathrm{~h}$. Levels of green fluorescence is represented in X-axis in arbitrary units (A.U) and cell count (Y-axis). Each concentration is given as a type line. The fluorescence of the highest NPs concentration $\left(100 \mathrm{mg} \mathrm{L}^{-1}\right)$, marked with a red area, was significantly different of the rest of treatments for both, PS-COOH and PS- $\mathrm{NH}_{2}(\mathrm{P}<0.001$ and $\mathrm{P}<0.001$; ANOVA) respectively. Control treatment are marked with a green area. Statistical analyses were performed on all females $(n=6)$, only one females was presented as example. 

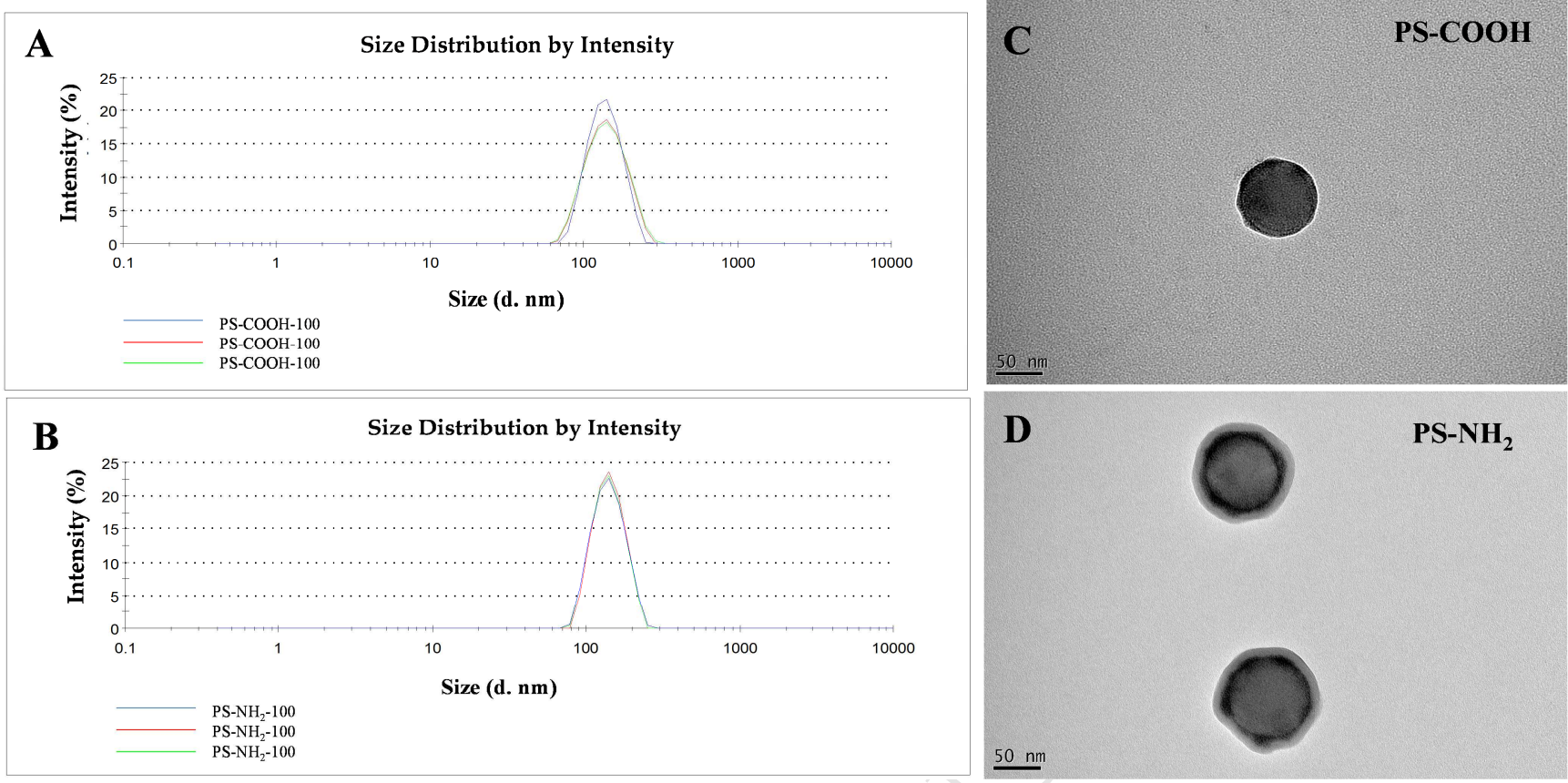

Figure 1 


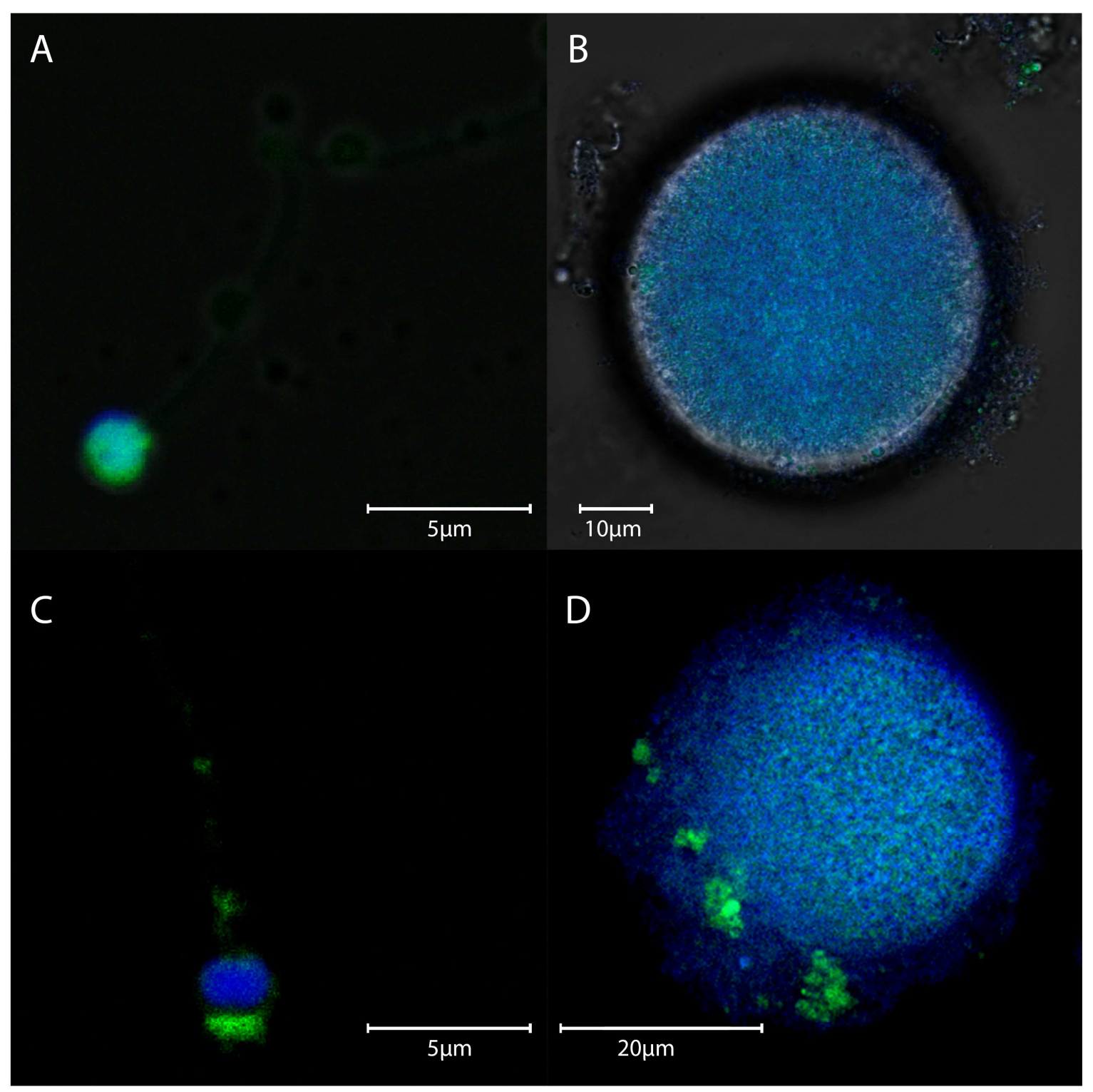


Spermatozoa exposed to PS-COOH

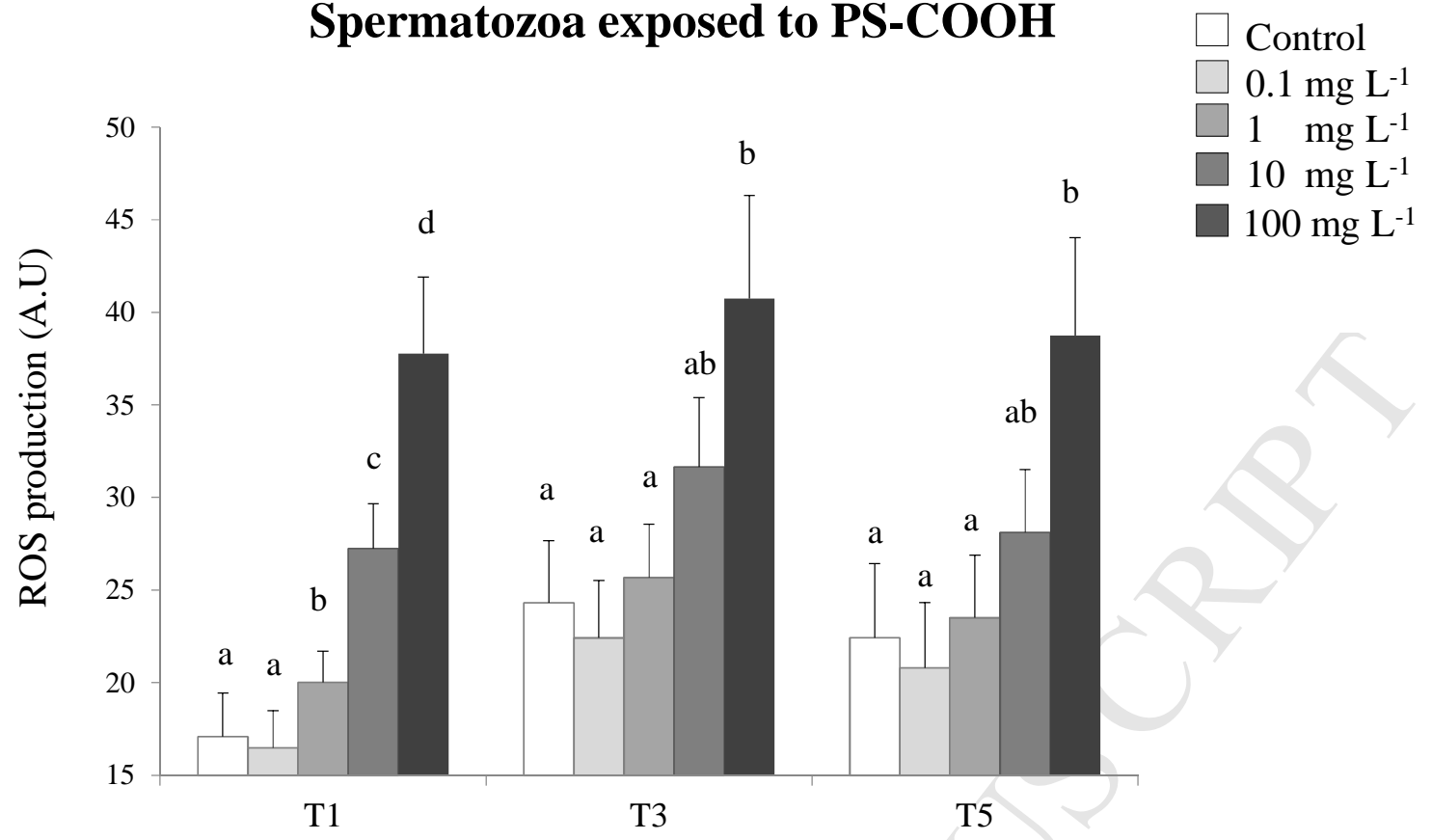

Time of exposure (h)

Figure 3. 